\title{
Does the diet of the Balearic population, a Mediterranean-type diet, ensure compliance with nutritional objectives for the Spanish population?
}

\author{
Josep A Tur*, Dora Romaguera and Antoni Pons \\ Laboratory of Physical Activity Sciences, University of the Balearic Islands (UIB) and Research Group on Community \\ Nutrition and Oxidative Stress, Research Institute on Health Sciences (IUNICS), E-07122 Palma de Mallorca, Spain
}

Submitted 18 May 2004: Accepted 25 October 2004

\begin{abstract}
Objectives: To assess the dietary habits of Balearic Islands' consumers who are successful in meeting current nutritional recommendations, to find clues for the development of future food-based dietary guidelines (FBDG) that would be relevant to this population.

Design: Cross-sectional nutritional survey carried out in the Balearic Islands between 1999 and 2000.

Subjects and methods: Dietary habits were assessed by means of 24-hour recall (two non-consecutive days: warm and cold season) and a food-frequency questionnaire in a random sample ( $n=1200$, aged $16-65$ years) living in private households. Differences in percentage of compliers with the intermediate nutritional objectives for the Spanish population and differences in food consumption patterns between genders and between high (above the upper quartile of intake) and low (below the lower quartile of intake) consumers of fat, saturated fatty acids (SFA), fibre, and fruit and vegetables were analysed.

Results: Gender differences were observed in nutrient and energy intakes, as well as in attainment of the recommendations. Less than $25 \%$ of the population reached the intermediate nutritional recommendations for iodine, fruit, carbohydrates, SFA, fibre and vegetables. Low fat/SFA and high fruit and vegetables/fibre consumers kept a diet in line with the traditional Balearic diet and prevailing dietary pyramids, which ensured better compliance with the nutritional goals.

Conclusions: The intermediate nutritional objectives for the Spanish population could be achieved through maintenance of the traditional Balearic diet, a Mediterraneantype diet in the Balearic population. Therefore, this dietary model could be used to develop FBDG relevant to this population.
\end{abstract}

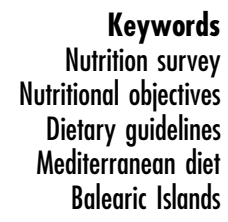

Keywords utritional objectives Dietary guidelines Balearic Islands
Currently, the scientific community acknowledges that diet may contribute to the delaying or prevention of an important number of chronic diseases. In Spain, inadequate diets have an important health and social impact. The consumption of fats, fruit and vegetables, dairy products, wine and alcohol, fish and meat, and the prevalence of obesity, for example, vary considerably among Spanish regions. As such, in our country diet and nutrition represent the main sources of variability in the geographic distribution of health indicators related to noninfectious diseases ${ }^{1}$.

Promoting adequate eating habits, which follow healthy dietary models, constitutes one of the most important components within heath promotion strategies. To achieve improvements in collective food intake, health authorities count on two tools of great value in terms of public health: nutritional objectives and food guidelines, and, more specifically, food guidelines based on country or regional food consumption patterns ${ }^{1,2}$.

Nutritional objectives for the Spanish population were developed based on a consensus meeting of the Spanish Society of Community Nutrition held in Bilbao in 2000 and sponsored by the World Health Organization. Intermediate and final nutrition objectives were defined at this time. Intermediate objectives were based on the analysis of current food and nutritional data from nutritional surveys. These intermediate objectives reflect reachable goals within the Spanish context given that $25 \%$ of the Spanish population is already meeting the nutritional objectives. Final nutritional objectives encompass long-term goals and are based on the best scientific evidence available at the present time. The nutritional objectives for the Spanish 
population create a rational framework for the development of dietary guidelines and nutritional policies in Spain, within a Mediterranean context ${ }^{1}$.

Food-based dietary guidelines (FBDG) should be established on what can realistically be achieved on the basis of a given socio-economic context. For this reason, they must be drawn from population-based epidemiological studies. For the elaboration of FBDG, it is essential to analyse prevalent food consumption patterns in order to be realistic for the population ${ }^{2}$. For instance, in the Mediterranean region, olive oil is the central element of Mediterranean-type diets, and it has traditionally been consumed in elevated quantities, which has led to high values of dietary lipids (25-40\% of energy). This fact has conflicted with nutritional objectives in Western countries that limit total fat intake to less than 30 or even $20 \%$ of energy. Moreover, olive oil is a key contributor to the healthy aspects attributed to the Mediterranean diet and it has been demonstrated that olive oil intake promotes higher vegetable intake in the Mediterranean area. As such, nutritional objectives in Mediterranean countries should address the reduction of saturated fat without modifying olive oil consumption ${ }^{3,4}$.

Recently, proposals have been made for international collaboration in the setting of FBDG. Food patterns of people at the upper end of intake of common nutritional targets in public health in a population (fat, saturated fatty acids (SFA), fibre, and fruit and vegetables) can be used as a model to identify potential target foods ${ }^{2}$.

The aim of the present study was to analyse compliance with the intermediate nutritional objectives for the Spanish population in a representative sample from the Balearic Islands, a Spanish Mediterranean region. Also, the compliance with nutritional objectives among those with a high or low intake of common nutritional targets in public health (fat, SFA, fruit and vegetables, and fibre) was studied to ascertain whether these individuals met current nutritional recommendations, and their food consumption patterns were analysed. This paper gives an insight into the dietary habits of Balearic Islands' consumers who are successful in meeting current nutritional recommendations, thereby providing clues for the development of future FBDG that would be relevant to this population.

\section{Methods}

The present analysis was performed using the database of the Nutrition Survey of the Balearic Islands that was carried out in 1999-2000; the methodology of this survey has been described elsewhere $e^{5,6}$ and is summarised here.

\section{Sample}

The target population consisted of all inhabitants, aged 16-65 years, living in the Balearic Islands, and the sample population was derived from residents aged $16-65$ years registered in the official population census of the Balearic
Islands. The sampling technique included stratification according to geographical area and municipality size (six strata), age (three strata) and sex of inhabitants, and randomisation into subgroups, with Balearic Islands' municipalities being the primary sampling units and individuals within these municipalities comprising the final sample units. Inclusion criteria stipulated to have been living in the Balearic Islands for 2 years before the study; this criterion was adopted to ensure that individuals were fully adapted to a regular life in the Balearic Islands, led usual activities and had adopted the customs of the immediate environment. Pregnant women were not considered in this study. The theoretical sample size was set at 1500 individuals, taking into account an anticipated $70 \%$ participation rate, and to provide a specific relative precision of $5 \%$ and a power of $90 \%$.

\section{Antbropometric measurements}

The anthropometric measures used in this study were: height, weight, body mass index (weight in $\mathrm{kg} /$ height $^{2}$ in metres), triceps skinfold thickness and body fat (\%), mid upper-arm circumference, mid upper-arm muscle area and body lean mass $(\mathrm{kg})$, waist and hip circumferences, and waist-to-hip ratio. One observer performed all anthropometric measurements, in order to avoid interobserver coefficients of variation.

Estimates of basal metabolic rate (BMR) were calculated from standard equations for Europeans based on weight, height, age and gender ${ }^{7}$.

\section{Food and nutrient intakes}

Two non-consecutive 24-hour diet recalls were carried out during the study period, one in the warm season (MaySeptember) and one in the cold season (NovemberMarch) to avoid the influence of seasonal variations. The recalls were administered in the subject's home. A welltrained dietitian administered the survey, verified and quantified the food records. To avoid bias resulting from day-to-day intake variability, the recalls were administered homogeneously from Monday to Sunday. To estimate volumes and portion sizes, household measures found in the subjects' own homes were used. Also, all participants filled in a quantitative food-frequency questionnaire covering 145 food items.

Information about food consumption patterns was obtained from the food-frequency questionnaire, whereas information on nutrient intake was derived from the average daily food consumption reported in the two 24-hour recalls. Conversion of food into nutrients was accomplished using an in-house computerised program based on Spanish $^{8,9}$ and European ${ }^{10}$ food composition tables, and complemented with food composition data available for Balearic food items ${ }^{11}$. Daily intake was compared with the intermediate and final nutritional objectives for the Spanish population ${ }^{1}$. Identification of underreporters of food intake was made using the 
Goldberg cut-off (energy intake (EI)/BMR $<1.14$ classified the individual as an underreporter $)^{12}$. Underreporters were not considered in this analysis.

To examine food and nutrient intake patterns as well as compliance with the Spanish nutritional objectives, consumption data for total fat (\% energy from fat), SFA (\% energy from SFA), fibre $\left(\mathrm{g} \mathrm{MJ}^{-1}\right)$ and fruit and vegetables $(\mathrm{g})$ were divided into quartiles and comparisons were made between the upper and lower quartile. Food patterns were analysed both in terms of the amount of food consumed (larger mean consumption of foods) and the number of consumers of the food group in order to ascertain differences in the consumption pattern between the upper and lower quartiles. A reference Balearic diet was identified, taking into account the dietary pattern of individuals belonging simultaneously to the lower quartiles of total fat and SFA intake and the upper quartiles of fibre and fruit and vegetables consumption. This reference diet could be chosen as a model when developing FBDG relevant to the Balearic population.

\section{Statistics}

Analyses were performed with SPSS version 12.0 (SPSS Inc., Chicago, IL, USA). Mean daily intake values of nutrients and standard deviation are shown. The unpaired Student $t$-test was used to test differences between gender means. Differences in percentage of compliers with the nutritional objectives for the Spanish population between genders and between the two consumer groups (low and high quartile of formerly mentioned nutrient or foods) were tested by means of the chi-square test (the latter analysis being adjusted by gender). Differences in mean consumption of a food in a food group between the two consumer groups were tested by the unpaired Student $t$-test. The proportion of consumers of a food group was considered different when the proportion of consumers in the two groups was found to differ by $5 \%$ or more.

\section{Results}

Subjects originally included in the study numbered 1554 , but the final sample size was 1200 individuals (77.2\% participation). Participation rate among females (87.5\%) was higher than among males (66.2\%). Non-participation rates include potential subjects declining to be interviewed as well as involuntary non-participation due to census error caused by address changes, missing persons or unavoidable impediments to survey collaboration. Some 634 individuals were identified as underreporters $(\mathrm{EI} / \mathrm{BMR}<1.14)$ and were excluded from the analysis of dietary patterns and nutrient intake so as to avoid respondent bias usually present in recall dietary methods.

Table 1 shows daily intakes of energy, nutrients and fruit and vegetables in men and women. Energy intake and energy intake per $\mathrm{kg}$ body weight were significantly higher in males than in females, but energy intake per kg
Table 1 Daily intakes of energy, nutrients, and fruit and vegetables (mean \pm standard deviation) in Balearic Islands' men and women

\begin{tabular}{|c|c|c|}
\hline & Men $(n=232)$ & Women $(n=334)$ \\
\hline Energy (kcal) & $2605.9 \pm 614$ & $2084.6 \pm 442^{\star \star \star}$ \\
\hline Energy (MJ)' & $10.9 \pm 2.6$ & $8.8 \pm 1.9^{\star \star \star}$ \\
\hline $\begin{array}{l}\text { Energy (kJ kg body } \\
\text { weight }^{-1} \text { ) }\end{array}$ & $142.8 \pm 33.6$ & $139.0 \pm 29.4^{\star \star \star}$ \\
\hline $\begin{array}{l}\text { Energy ( } \mathrm{kJ} \mathrm{kg} \mathrm{lean} \\
\text { body } \text { mass }^{-1} \text { ) }\end{array}$ & $189.9 \pm 56.3$ & $229.5 \pm 62.0^{\star \star \star}$ \\
\hline Protein (\% energy) & $16.4 \pm 3.9$ & $16.6 \pm 3.9$ \\
\hline Carbohydrate (\% energy) & $41.6 \pm 8.2$ & $42.9 \pm 8.5^{\star}$ \\
\hline Sugar (\% energy) & $18.0 \pm 8.7$ & $20.8 \pm 8.4^{*}$ \\
\hline $\begin{array}{l}\text { Complex carbohydrate } \\
\text { (\% energy) }\end{array}$ & $23.2 \pm 8.5$ & $21.8 \pm 8.8^{*}$ \\
\hline Fibre $(\mathrm{g})$ & $20.7 \pm 9.6$ & $18.2 \pm 9.7^{\star}$ \\
\hline Fibre/energy $\left(\mathrm{g} \mathrm{MJ}^{-1}\right)$ & $1.9 \pm 0.8$ & $2.1 \pm 0.9^{\star \star}$ \\
\hline Total fat (\% energy) & $39.4 \pm 7.6$ & $39.4 \pm 7.5$ \\
\hline SFA ( $\%$ energy) & $13.4 \pm 3.2$ & $13.4 \pm 3.6$ \\
\hline PUFA (\% energy) & $5.0 \pm 2.3$ & $4.9 \pm 2.3$ \\
\hline MUFA ( $\%$ energy) & $17.2 \pm 4.2$ & $17.1 \pm 4.1$ \\
\hline Cholesterol (mg) & $512 \pm 252$ & $378 \pm 194^{\star \star *}$ \\
\hline Cholesterol $\left(\mathrm{mg} \mathrm{MJ}^{-1}\right)$ & $46.9 \pm 20.4$ & $43.6 \pm 21.3^{\star \star \star}$ \\
\hline Cholesterol/SFA ratio & $63.8 \pm 34.4$ & $48.2 \pm 28.6^{\star \star \star}$ \\
\hline Alcohol (g) & $8.3 \pm 14.9$ & $2.6 \pm 7.6^{\star \star \star}$ \\
\hline Alcohol (\% energy) & $2.6 \pm 5.0$ & $1.0 \pm 2.8^{\star \star \star}$ \\
\hline Fruit $(\mathrm{g})$ & $207.3 \pm 392.4$ & $173.5 \pm 218.2^{\star \star \star}$ \\
\hline Vegetables (g) & $194.4 \pm 200.0$ & $215.5 \pm 204.0^{\star \star \star *}$ \\
\hline $\mathrm{F} \& \mathrm{~V}(\mathrm{~g})$ & $402 \pm 263$ & $389 \pm 235$ \\
\hline Folate $(\mu \mathrm{g})$ & $356.09 \pm 190.98$ & $308.38 \pm 161.71^{\star \star *}$ \\
\hline Calcium (mg) & $1057.57 \pm 1948.41$ & $902.62 \pm 370.13^{\star \star \star}$ \\
\hline lodine $(\mu \mathrm{g})$ & $95.70 \pm 40.00$ & $89.9 \pm 44.22^{\star \star \star}$ \\
\hline
\end{tabular}

SFA - saturated fatty acids; PUFA - polyunsaturated fatty acids; MUFA monounsaturated fatty acids; F\&V - fruit and vegetables.

Significant differences between men and women $\left({ }^{*}, P<0.05 ;{ }^{\star *}, P<0.01\right.$; $* \star *, P<0.001$ ) by unpaired Student's $t$-test.

Only people who did not underreport their energy intake (energy intake/ basal metabolic rate $\geq 1.14$ ) were considered for this analysis.

lean body mass was greater in women. The contribution of carbohydrate to energy was higher in women; women obtained more energy from sugars than did men, and men obtained more energy from complex carbohydrate than did women. No differences were observed in the percentage of energy intake from proteins and fat between genders. Cholesterol and fibre expressed per energy intake were higher in men. Men's cholesterol/SFA ratio, as well as alcohol intake, was also higher than women's. Men showed a significantly higher intake of fruit but a lower intake of vegetables than women. Nevertheless, when both food groups were considered together (consumption of fruit in grams plus consumption of vegetables in grams), gender differences were no longer statistically significant. Men also showed significantly greater intakes of iodine, calcium and folate.

Table 2 shows the percentage of compliers with the intermediate nutritional objectives for the Spanish population in the whole population, males and females. Intermediate objectives were chosen for this comparison since $25 \%$ of the Spanish population is already supposed to meet these goals ${ }^{1}$. However, for some nutrients and food items, less than $25 \%$ of the Balearic population is meeting the requirements. These nutrients are iodine, 
Table 2 Proportion of compliers with the intermediate nutritional objectives for the Spanish population in the Balearic Islands' population

\begin{tabular}{|c|c|c|c|c|}
\hline \multirow{2}{*}{$\begin{array}{l}\text { Intermediate nutritional objectives } \\
\text { for the Spanish population }{ }^{1}\end{array}$} & & \multicolumn{3}{|c|}{$\begin{array}{c}\text { Percentage of compliers with the intermediate } \\
\text { nutritional objectives }\end{array}$} \\
\hline & & All $(n=566)$ & Males $(n=232)$ & Females $(n=334)$ \\
\hline Dietary fibre & $>22$ g day $^{-1}$ & 26.1 & 35.1 & 24.1 \\
\hline Folate & $>300 \mu \mathrm{g} \mathrm{day}^{-1}$ & 47.7 & 52.3 & 46.8 \\
\hline Calcium & $\geq 800 \mathrm{mg} \mathrm{day}^{-1}$ & 56.0 & 59.7 & 55.2 \\
\hline SFA (\% energy) & $\leq 10 \%$ & 16.1 & 12.1 & 16.9 \\
\hline MUFA (\% energy) & $20 \%$ & 75.8 & 75.6 & $75.9^{\mathrm{NS}}$ \\
\hline PUFA (\% energy) & $5 \%$ & 40.8 & 45.6 & 39.8 \\
\hline Cholesterol & $<350 \mathrm{mg} \mathrm{day}^{-1}$ & 49.0 & 31.0 & 52.9 \\
\hline Carbohydrate (\% energy) & $>50 \%$ & 18.1 & 13.9 & 19.0 \\
\hline Fruit & $>300 \mathrm{~g} \mathrm{day}^{-1}$ & 17.1 & 17.1 & $17.2^{\mathrm{NS}}$ \\
\hline
\end{tabular}

SFA - saturated fatty acids; PUFA - polyunsaturated fatty acids; MUFA - monounsaturated fatty acids.

${ }_{N S}$ Differences between gender percentages are not statistically significant. All other differences are statistically significant (chi-square test; $P<0.05)$.

Underreporters have been excluded from this analysis.

fruit, carbohydrate, SFA, fibre and vegetables. When the compliance with nutritional objectives is analysed separately by sex, the percentage of males meeting the goals is significantly higher than the percentage of females for dietary fibre, polyunsaturated fatty acids (PUFA), folate, calcium and iodine, whereas females' compliance with the recommended daily intake of cholesterol, carbohydrate, SFA, vegetables and total fat is greater than males'. Nevertheless, despite these differences, the weaknesses in the compliance with the intermediate nutritional objectives in males and females are the same as those in the overall population: iodine, fruit, carbohydrate, SFA, fibre and vegetables.
In Table 3, percentages of compliers with the intermediate nutritional objectives in the lower and upper quartiles of total fat, SFA, fruit and vegetables and fibre consumption are shown. We observe that those in the lower quartile of fat and SFA intake and the upper quartile of intake of fruit and vegetables and fibre show greater compliance (more compliers) with the nutritional objectives. Therefore it was hypothesised that their dietary pattern could be used to develop FBDG based on the Balearic diet as it permits achievement of the current nutritional recommendations.

The food consumption patterns for consumers in low and high fat, SFA, fibre and fruit and vegetables quartiles

Table 3 Proportion of compliers with the intermediate nutritional objectives for the Spanish population among low and high consumers of total fat (\% energy), saturated fatty acids (SFA) (\% energy), fruit and vegetables (F\&V) $(\mathrm{g})$ and fibre $\left(\mathrm{g} \mathrm{MJ}^{-1}\right)$ in the Balearic Islands

\begin{tabular}{|c|c|c|c|c|c|c|c|c|c|}
\hline \multirow{3}{*}{$\begin{array}{l}\text { Intermediate nutritional } \\
\text { objectives for the } \\
\text { Spanish population }{ }^{1}\end{array}$} & & \multicolumn{8}{|c|}{ Percentage of compliers with the intermediate nutritional objectives } \\
\hline & & \multicolumn{2}{|c|}{$\begin{array}{l}\text { Fat intake } \\
\text { (\% energy) }\end{array}$} & \multicolumn{2}{|c|}{$\begin{array}{l}\text { SFA intake } \\
\text { (\% energy) }\end{array}$} & \multicolumn{2}{|c|}{$F \& V(g)$} & \multicolumn{2}{|c|}{ Fibre $\left(\mathrm{g} \mathrm{MJ}^{-1}\right)$} \\
\hline & & $\begin{array}{c}\text { Low } \\
(<34.7 \%)\end{array}$ & $\begin{array}{l}\text { High } \\
(>44.1 \%)\end{array}$ & $\begin{array}{l}\text { Low } \\
(<10.9 \%)\end{array}$ & $\begin{array}{c}\text { High } \\
(>15.8 \%)\end{array}$ & $\begin{array}{c}\text { Low } \\
(<154 \mathrm{~g})\end{array}$ & $\begin{array}{c}\text { High } \\
(>477 \mathrm{~g})\end{array}$ & $\begin{array}{c}\text { Low } \\
\left(<1.45 \mathrm{~g} \mathrm{MJ}^{-1}\right)\end{array}$ & $\begin{array}{c}\text { High } \\
\left(>2.53 \mathrm{~g} \mathrm{MJ}^{-1}\right)\end{array}$ \\
\hline Dietary fibre & $>22$ g day $^{-1}$ & 25.6 & 16.2 & 37.1 & 11.1 & 27.2 & 29.5 & 0.3 & 73.1 \\
\hline Folate & $>300 \mu \mathrm{g} \mathrm{day}^{-1}$ & 54.2 & 33.8 & 60.1 & 33.2 & 44.6 & 52.8 & 12.8 & 78.2 \\
\hline Calcium & $\geq 800 \mathrm{mg} \mathrm{day}^{-1}$ & 61.1 & 49.7 & 39.9 & 66.5 & 53.8 & $59.7^{\mathrm{NS}}$ & 53.4 & $60.0^{\mathrm{NS}}$ \\
\hline lodine & $150 \mu \mathrm{g} \mathrm{day}^{-1}$ & 16.9 & 10.3 & 11.3 & $9.2^{\mathrm{NS}}$ & 8.0 & 17.0 & 8.5 & $13.5^{\mathrm{NS}}$ \\
\hline Total fat (\% energy) & $\leq 35 \%$ & 100.0 & 0.0 & 60.5 & 2.2 & 22.0 & 35.4 & 16.6 & 35.6 \\
\hline SFA (\% energy) & $\leq 10 \%$ & 43.5 & 0.6 & 66.3 & 0.0 & 14.7 & 21.6 & 6.8 & 30.5 \\
\hline MUFA (\% energy) & $20 \%$ & 98.7 & 29.7 & 86.9 & 60.7 & 78.8 & $77.7^{\mathrm{NS}}$ & 70.3 & $77.1^{\mathrm{NS}}$ \\
\hline PUFA (\% energy) & $5 \%$ & 29.6 & 49.4 & 45.0 & 39.6 & 36.1 & $39.3^{\mathrm{NS}}$ & 40.1 & 45.5 \\
\hline Cholesterol & $<350 \mathrm{mg} \mathrm{day}^{-1}$ & 62.5 & 35.0 & 58.1 & 39.3 & 51.7 & $45.6^{\mathrm{NS}}$ & 40.6 & 61.1 \\
\hline Carbohydrate (\% energy) & $>50 \%$ & 58.1 & 0.0 & 46.0 & 1.4 & 18.0 & 24.6 & 9.8 & 22.5 \\
\hline Fruit & $>300 \mathrm{~g} \mathrm{day}^{-1}$ & 21.6 & 19.1 & 21.6 & 15.8 & 0.0 & 66.6 & 15.8 & $18.9^{\mathrm{NS}}$ \\
\hline Vegetables & $>250 \mathrm{~g} \mathrm{day}^{-1}$ & 29.9 & 24.4 & 33.0 & 20.5 & 0.0 & 86.2 & 19.6 & 29.8 \\
\hline
\end{tabular}

SFA - saturated fatty acids; PUFA - polyunsaturated fatty acids; MUFA - monounsaturated fatty acids.

Low intake is defined as an intake below the lower quartile of intake. High intake is defined as an intake above the upper quartile of intake. Values in parentheses show the cut-off point of intake for the lower and upper quartiles.

${ }_{N S}$ Difference in percentages between lower and upper quartiles is not significant. All other differences between quartile percentages are statistically significant (chi-square test; $P<0.05$ ).

Gender-adjusted analysis. Underreporters have been excluded from this analysis. 
are shown in Table 4. In some cases a certain population group showed larger mean consumption and more consumers of the food group, and in some cases there was either a larger mean consumption of foods in the food group or more consumers of foods in the food group, contributing to the difference in the consumption pattern. As summarised in Table 5, overall low consumers of fat and SFA and high consumers of fibre and fruit and vegetables showed a food consumption pattern similar to that recommended in current food group pyramids ${ }^{13,14}$ and in line with the traditional Mediterranean dietary pattern, which is characterised by high intakes of fish, olive oil, fruit and vegetables, poultry, nuts, skimmed milk and cereals.

We found that low consumers of total fat and SFA showed better compliance with the recommended fruit and vegetables intake. It was decided to analyse whether or not reducing total fat intake would be a good strategy to increase consumption of fruit and vegetables in this Mediterranean region. In Fig. 1a, fruit and vegetables intake $\left(\mathrm{g} \mathrm{MJ}^{-1}\right.$ day $\left.^{-1}\right)$ is plotted against quartile of total fat (\% energy) intake. The resulting U-shaped chart shows that both low (quartile 1) and high (quartile 4) fat consumers present higher fruit and vegetables consumption than people in the middle quartiles (2 and 3) of fat intake. This is not so when fruit and vegetables intake $\left(\mathrm{g} \mathrm{MJ}^{-1} \mathrm{day}^{-1}\right)$ is plotted against quartile of SFA (\% energy) (Fig. 1b). Consumption of fruit and vegetables decreases as the intake of saturated fat increases. Figure 1c shows that the highest intake of fruit and vegetables $\left(\mathrm{g} \mathrm{MJ}^{-1} \mathrm{day}^{-1}\right)$ is observed in quartile 2 of monounsaturated fatty acids (MUFA) intake, in which the mean value is around $17 \%$ of total energy intake from MUFA.

\section{Discussion}

The final sample size was 1200 individuals (77.2\% participation). More females (58.5\%) than males (41.5\%) participated in this study. Nevertheless, according to the last census of the Balearic population, the gender distribution of the sample did not differ from the gender distribution existing currently in the whole Balearic population $^{15}$. A high percentage of the final sample did not report their energy intake accurately and therefore they were excluded from the analysis of dietary patterns. A similar proportion of underreporters was obtained in previous nutritional surveys ${ }^{16-19}$. Dietary assessment methods are subject to systematic respondent biases since respondents may under- or overestimate the consumption of certain food groups. Exclusion of underreporters helps to minimise this type of measurement error and increases the validity of the data; however, sample size was decreased and therefore the results might be less representative. Nevertheless, taking into account that underreporting is systematically confined to particular subgroups of the sample and underreporters show specific dietary patterns (high consumption of 'good foods' and low consumption of 'bad foods', together with high prevalence of inadequate intakes of micronutrients; data not shown), we decided to exclude underreporters despite the considerable decrease in sample size.

Dietary guidelines need to be based on a robust assessment of the available scientific information on diet and the maintenance of good health. This assessment needs to include an evaluation of the prevailing diet and nutrient intakes compared with any recommended optimum. Any dietary guidelines need to be pragmatic. A stepwise approach may be needed to address any large disparities between actual and ideal dietary habits ${ }^{20}$.

This study demonstrates that there are certain gender differences in the consumption of energy, nutrients and food items. Females show better compliance with the recommendations for cholesterol, carbohydrates, SFA, vegetables and total fat than do males. This can be attributed to the greater nutritional knowledge and concerns about body weight and health status among the female population ${ }^{21}$. On the other hand, females are less likely to achieve the recommended intakes of micronutrients, fibre and PUFA. It has to be pointed out that women are more likely to present inadequacies in the micronutrient content of their diet than are men, since their energy needs are lower but their requirements for micronutrients can be even higher than men's ${ }^{22}$. The percentage of compliers with the recommended MUFA and fruit intakes did not differ between genders.

Despite the differences mentioned above, weaknesses in compliance with the nutritional objectives in males and females are similar to those in the overall population: iodine, fruit, carbohydrate, SFA, fibre and vegetables. Less than $25 \%$ of the Balearic population is currently meeting the intermediate nutritional recommendations for these foods and nutrients. Particular emphasis should be placed on addressing these issues to successfully reach the intermediate objectives and long-term final nutritional objectives.

Dietary fibre intake in the Balearic Islands' population is quite far from both the Spanish intermediate and final nutrition objectives. It is obvious that low consumption of vegetables and carbohydrate is accompanied by a low intake of fibre, since the main dietary sources of fibre in this sample are cereals (mainly high-fibre bread), fruit and vegetables. The largest disparities with the recommended fat intake in the Balearic Islands' population are observed for the intake of SFA. Main sources of fat are added fats (margarine, oil, etc.), but also animal foods (milk, meat, sausages, eggs, cheese, etc.) that provide saturated fats ${ }^{23}$. We observe that intakes of iodine are also far from the recommended levels. Actually, only $10.4 \%$ of this population consumes $150 \mu \mathrm{gday}^{-1}$. To date, dietary habits in Spain may play a role in iodine deficiency ${ }^{24}$. Epidemiological studies have demonstrated the existence of endemic goitre and mild iodine deficiency in Andalucía, 


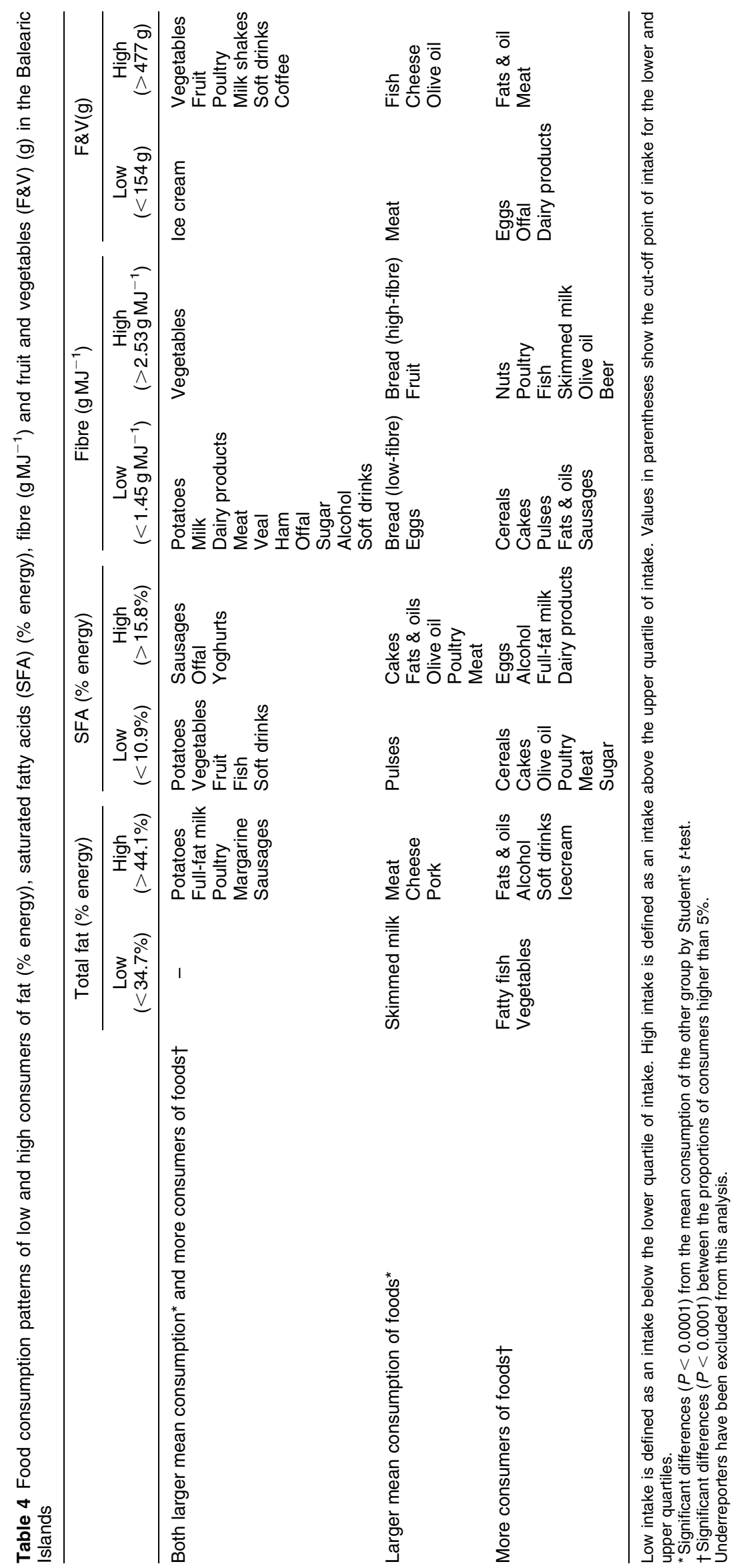

JA Tur et al. 
Table 5 Reference diet for the development of food-based dietary guidelines. Food consumption pattern of individuals belonging simultaneously to the lower quartile of fat and saturated fatty acids (\% energy) and the upper quartile of fruit and vegetables (g) and fibre $\left(\mathrm{g} \mathrm{MJ}^{-1}\right)$, expressed as the frequency of consumption and amount consumed (servings day $^{-1} /$ servings week ${ }^{-1}$ ) and indicating the most consumed types of food within the food group

\begin{tabular}{|c|c|c|}
\hline Food group & Amount/frequency & $\begin{array}{l}\text { Most consumed food items } \\
\text { within the food group }\end{array}$ \\
\hline Cereals & 2 servings day ${ }^{-1}$ & $\begin{array}{l}\text { pasta, rice, } \\
\text { breakfast cereals }\end{array}$ \\
\hline Bread & 1.3 servings day ${ }^{-1}$ & $\begin{array}{l}\text { white bread, } \\
\text { whole-grain bread }\end{array}$ \\
\hline Potatoes & 1 serving week ${ }^{-1}$ & \\
\hline $\begin{array}{l}\text { Meat and } \\
\text { butchery } \\
\text { products }\end{array}$ & 3 servings week ${ }^{-1}$ & $\begin{array}{c}\text { poultry, pork, } \\
\text { beef, ham }\end{array}$ \\
\hline $\begin{array}{l}\text { Fish and } \\
\text { shellfish }\end{array}$ & 3 servings week ${ }^{-1}$ & \\
\hline Eggs & 1.5 servings week $^{-1}$ & \\
\hline Legumes & 1 serving week ${ }^{-1}$ & $\begin{array}{l}\text { lentils, chickpeas, } \\
\text { beans }\end{array}$ \\
\hline Nuts & 2 servings week ${ }^{-1}$ & $\begin{array}{l}\text { almonds, peanut, } \\
\text { hazelnut }\end{array}$ \\
\hline Fruit & 3 servings day ${ }^{-1}$ & orange, apple, apricot \\
\hline Vegetables & 2 servings day ${ }^{-1}$ & $\begin{array}{l}\text { lettuce, tomato, } \\
\text { carrot, spinach }\end{array}$ \\
\hline Dairy products & 3 servings day ${ }^{-1}$ & $\begin{array}{l}\text { skimmed milk, } \\
\text { yoghurt, cheese }\end{array}$ \\
\hline $\begin{array}{l}\text { Sweets, cakes } \\
\text { and sugar }\end{array}$ & 2 servings day ${ }^{-1}$ & $\begin{array}{l}\text { sugar, jam, } \\
\text { canned fruit, juice }\end{array}$ \\
\hline Olive oil & 1 serving day ${ }^{-1}$ & \\
\hline $\begin{array}{l}\text { Other oils } \\
\text { and fats }\end{array}$ & 3 servings week ${ }^{-1}$ & \\
\hline Alcohol & $2-3$ glasses week ${ }^{-1}$ & table wine, beer \\
\hline
\end{tabular}

Asturias, Catalunya, Extremadura, Galicia and Castilla. However, no data have been collected in the Balearic Islands ${ }^{25}$. Nevertheless, it is very likely that the observed low intakes of iodine in this population reflect errors in the conversion of foods into nutrients using food composition tables. There are not many data available about the iodine content of foods, which may vary depending on the characteristics of the soil, etc. ${ }^{8}$.

Analysis of food patterns of low and high consumers of specific public health nutrition targets (SFA, fat, fibre, fruit and vegetables) can be used as a model to develop realistic dietary guidelines in a specific population. This study demonstrates that low consumers (consumption below the lower quartile) of total fat and SFA and high consumers (consumption above the upper quartile) of fruit and vegetables and fibre show better compliance with the intermediate nutritional objectives than do high consumers of total fat and SFA and low consumers of fruit and vegetables and fibre. Overall, their food pattern is characterised by high intakes of fish, olive oil, fruit and vegetables, poultry, nuts, skimmed milk and cereals. The amount and frequency of food group consumption (servings $\mathrm{day}^{-1} /$ servings week $^{-1}$ ) are similar those recommended in most food group pyramids ${ }^{13,14}$. Moreover, the types of foods are similar to those found in the traditional Mediterranean $\operatorname{diet}^{26}$ and traditional Balearic
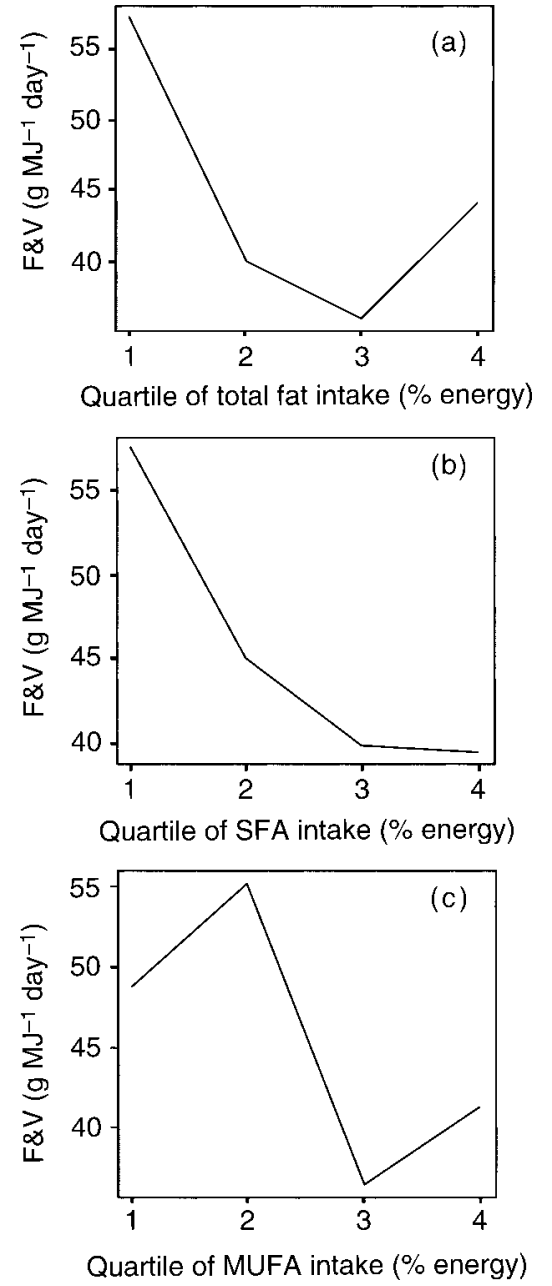

Fig. 1 Mean consumption of fruit and vegetables (F\&V) $\left(\mathrm{g} \mathrm{MJ}^{-1}\right.$ day $^{-1}$ ) in each quartile of (a) total fat intake (\% energy), (b) saturated fatty acids (SFA) intake (\% energy) and (c) monounsaturated fatty acids (MUFA) intake (\% energy)

diet present at the beginning of the 20th century ${ }^{5}$, before the onset of the so-called 'nutrition transition' that involves loss of the traditional Mediterranean diet towards a more Western-type diet ${ }^{27,28}$.

Therefore the traditional Mediterranean-Balearic diet can be used to develop FBDG in this context, given the feasibility of implementing this dietary model in the Islands. The promotion of this food pattern would constitute a good strategy to preserve this diet and correct the observed departure from the Balearic Mediterranean diet. The wide availability of olive oil, fresh fruit, vegetables and fish in the Balearic Islands makes this approach sustainable.

However, the lipid content of the Mediterranean diet is usually high, ranging from 25 to $40 \%$ of energy intake $\mathrm{e}^{3,4}$. According to the present study, low total fat and SFA consumers present better compliance with the nutritional objectives. It was analysed whether or not reduction of total fat would be advisable to improve the dietary profile of this population, particularly fruit and vegetables 
consumption. The main source of lipids in Mediterranean countries is olive oil, and different authors have argued that olive oil promotes vegetables consumption. Figure 1 demonstrates that it is not total fat but SFA that determines a low intake of fruit and vegetables. Very low MUFA consumers (quartile 1) also present lower intakes of fruit and vegetables than people consuming around $17 \%$ of energy from MUFA. These results suggest that high intake of fat but low intake of SFA could be associated with higher fruit and vegetables consumption, perhaps due to typical combined consumption of vegetables with olive oil in Mediterranean regions ${ }^{4}$. It has to be pointed out that low fat consumers in this population are eating around $35 \%$ of energy from total fat, a quantity that would be considered high if compared with nutritional goals in nonMediterranean countries ${ }^{3,4}$. Therefore, reduction of the fat content of the diet should be restricted to reducing SFA but maintaining the MUFA content of the diet around 15-20\%. This can be achieved by consuming skimmed milk instead of full-fat milk and decreasing the consumption of meat, sausages, dairy products, cakes and other sweets, etc.

\section{Summary}

The traditional Balearic diet seems to ensure compliance with the intermediate nutritional objectives for the Spanish population and can be used as a model to develop FBDG. A percentage of energy from fat of about 35\% ensures adequate dietary profiles as long as most of this energy is provided by unsaturated fat.

\section{Acknowledgements}

This work was granted by the Spanish Ministry of Health (Projects 97/0007-00, 97/0007-01 and PI021593), and also by the Balearic Islands' Councillor of Health and Consumerism (Project 17/2003). The authors are also grateful to Ms M Colomer, Mr M Moñino and Ms M García for technical assistance.

\section{References}

1 Serra-Majem L, Aranceta J, on behalf of the SENC Working Group on Nutritional Objectives for the Spanish Population. Nutritional objectives for the Spanish population. Consensus from the Spanish Society of Community Nutrition. Public Health Nutrition 2001; 4: 1409-13.

2 Becker W, Gibney M, Kearney J, Löwik M, Serra-Majem Ll, Wiseman M. Foreword. British Journal of Nutrition 1999; 81(Suppl. 2): S29

3 Serra-Majem L, Ngo de la Cruz J, Ribas L, Tur JA. Olive oil and the Mediterranean diet: beyond the rhetoric. European Journal of Clinical Nutrition 2003; 57(Suppl. 1): S2-7.

4 Trichopoulos D. In defence of the Mediterranean diet. European Journal of Clinical Nutrition 2002; 56: 928-9.

5 Tur JA, Lladó M, Albertí RC, Pons A. Changes on nutrient and food intakes in Mallorca throughout the XXth century. Revista Española de Nutrición Comunitaria 2004; 10: 6-16.

6 Tur JA, Romaguera D, Pons A. Food consumption patterns in a Mediterranean region: is the Mediterranean diet still present? Annals of Nutrition \& Metabolism 2004; 48 193-201.

7 Scientific Committee for Food of the European Community. Nutrients and Energy Intakes for the European Community. Reports of the Scientific Committee for Food, 31st series. Luxembourg: Commission of the European Communities, Directorate General Industry, 1993.

8 Mataix J, Mañas M, Llopis J, Martínez de Victoria E, Juan J, Borregón A. Tablas de Composición de Alimentos Españoles, 4th ed. Granada: INTA-Universidad de Granada, 2004.

9 Moreiras O, Carbajal A, Cabrera L, Cuadrado C. Tablas de Composición de Alimentos, 7th ed. Madrid: Pirámide, 2003.

10 Feinberg M, Favier JC, Ireland-Ripert J. Répertoire Géneral des Aliments. París: Tec \& Doc Lavoisier, 1995.

11 Ripoll L, ed. Cocina de las Islas Baleares, 5th ed. Palma de Mallorca: L Ripoll, 1992.

12 Goldberg GR, Black AE, Jebb SA, Cole TJ, Murgatroyd PR, Coward WA, et al. Critical evaluation of energy physiology. I. Derivation of cut-off limits to identify under-recording. European Journal of Clinical Nutrition 1991; 45: 569-81.

13 Aranceta J, Serra-Majem L, on behalf the Working Party for the Development of Food-Based Dietary Guidelines for the Spanish Population. Dietary guidelines for the Spanish population. Public Health Nutrition 2001; 4: 1403-8.

14 Willett WC, Sacks F, Trichopoulou A, Drescher G, Ferro-Luzzi A, Helsing E, et al. Mediterranean diet pyramid: a cultural model for healthy eating. American Journal of Clinical Nutrition 1995; 61(Suppl. 6): 1402S-6S.

15 Instituto Nacional de Estadística (INE). Censo de Población y Residencia 2001. Madrid: INE, 2003.

16 Johansson L, Solvoll K, Bjorneboe GE, Drevon CA. Underand overreporting of energy intake related to weight status and lifestyle in a nationwide sample. American Journal of Clinical Nutrition 1998; 68: 266-74.

17 Black AE, Cole TJ. Biased over- or under-reporting is characteristic of individuals whether over time or by different assessment methods. Journal of the American Dietetic Association 2001; 101: 70-80.

18 Johansson G, Wikman A, Ahren AM, Hallmans G, Johansson I. Underreporting of energy intake in repeated 24-hour recalls related to gender, age, weight status, day of interview, educational level, reported food intake, smoking habits and area of living. Public Health Nutrition 2001; 4: 919-27.

19 Scagliusi FB, Polacow VO, Artioli GG, Benatti FB, Lancha AH Jr. Selective underreporting of energy intake in women: magnitude, determinants, and effect of training. Journal of the American Dietetic Association 2003; 103: 1306-13.

20 Wearne SJ, Day MJL. Clues for the development of foodbased dietary guidelines: how are dietary targets being achieved by UK consumers? British Journal of Nutrition 1999; 81(Suppl. 2): S119-26.

21 Serra-Majem L, Ribas L, Pérez C, Roman B, Aranceta J. Hábitos alimentarios y consumo de alimentos en la población infantil y juvenil española (1998-2000): variables socioeconómicas y geográficas. Medicina Clinica 2003; 121: 126-31.

22 Aranceta J, Serra-Majem L, Pérez-Rodrigo C, Llopis J, Mataix J, Ribas L, et al. Vitamins in Spanish food patterns: The eVe Study. Public Health Nutrition 2001; 4: 1317-23.

23 Tur JA. Nutritional Survey of the Balearic Islands (ENIB, 1999-2000). Revista de Ciència 2002; 27-30.

24 Serra-Majem L, Lloveras G, Vila L, Salleras L. Estrategias para la prevención y el control de los trastornos ocasionados por la deficiencia de yodo en Catalunya (1983-1992). Endocrinología (Barcelona) 1997; 109: 425-30. 
25 Serna-Arnaiz MC, Serra-Majem L, Gasco-Eguiluz E, MunozMarquez J, Ribas L, Escobar del Rey F. Current situation of goiter endemic and iodine intake in the population of the Pyrenees and the Segria region of Lleida. Atención Primaria 1998; 10: 642-8.

26 Trichopoulou A, Costacou T, Christina B, Trichopoulou D. Adherence to a Mediterranean diet and survival in a Greek population. New England Journal of Medicine 2003; 348 : $2599-608$.

27 Aranceta J. Spanish food patterns. Public Health Nutrition 2001; 4: 1399-402.

28 Moreno LA, Sarría A, Popkin BM. The nutrition transition in Spain: a European Mediterranean country. European Journal of Clinical Nutrition 2002; 56: 992-1003. 